du portugais. L'auteur en conclut qu'il y a urgence à produire du matériel pédagogique et à former les enseignants si on veut réellement enseigner le portugais comme langue seconde, sans remettre en cause l'enseignement en langue maternelle. Conceição Siopa (p. 183-197) se penche ensuite sur la nécessité de normaliser le portugais des étudiants de l'université Eduardo Mondlane, compte tenu $\mathrm{du}$ fait que pour eux le portugais est très majoritairement une langue seconde.

L'intérêt porté par les gouvernements africains eux-mêmes à l'éducation, n'est pas escamoté dans l'ensemble de ces articles : il apparaît que cet intérêt reste trop souvent à l'état de déclaration. Les problèmes qui se posent sont indéfiniment les mêmes, et les solutions, connues, ne sont pas appliquées. Mais ce n'était pas le but de cet ouvrage, qui, sans prétendre faire le tour d'une question complexe, montre déjà une série de réflexions approfondies et d'études qui contribueront à la qualité de l'éducation dans les Palop, et, c'était là son but principal, à une meilleure prise de conscience du rôle que peut y jouer le Portugal dans l'intérêt des populations des Palop.

Août 2006, Jean-Pierre Chavagne

\title{
António Costa Pinto \& Nuno Severiano Teixeira (eds), A Europa do Sul e a Construção da União Europeia 1945-2000, Lisboa, Imprensa de Ciências Sociais, 2005, ISBN : 972-671-155-X.
}

Sebastián Royo (ed.), Portugal, Espanha e a Integração Europeia: Um Balanço, Lisboa, Imprensa de Ciências Sociais, 2005, ISBN : 972-671-149-5.

Nesta recensão, resolvemos juntar duas publicações recentes da editora Imprensa de Ciências Sociais ligada ao Instituto de Ciências Sociais da Universidade de Lisboa. Com efeito, ambas visam comparar as diversas experiências dos países da Europa do Sul no que diz respeito à integração na União Europeia, transição para a democracia e outros aspectos relevantes da sua evolução económica, política e social no Pós-Guerra. Deve-se no entanto precisar que a obra referida em segundo lugar, tem um alcance geográfico mais limitado, concentrando-se nos casos português e espanhol embora contenha duas contribuições que procuram retirar daí ensinamentos para os países da Europa ex-comunista. No todo, e não considerando os prefácios e introdução, são dezanove ensaios que se debruçam ora sobre o conjunto da Europa do Sul, ora sobre países isolados (Portugal, Espanha, Grécia, Itália) analisando, por vezes, sectores ou áreas específicos. Seja como for, as vicissitudes da integração destes países no processo europeu e das suas diferentes fases estão particularmente no centro das preocupações da generalidade dos autores. Deve-se, primeiro que tudo, saudar a actividade do Instituto de Ciências Sociais no domínio das comparações internacionais envolvendo processos de transformação a vários níveis, bem representada por estas duas obras e de que Portugal se encontra carenciado, sobretudo em termos de trabalhos de qualidade e com bom conhecimento de causa.

O primeiro livro organizado por António Costa Pinto e Nuno Severiano Teixeira corresponde a um projecto financiado pela Fundação para a Ciência e a Tecnologia no âmbito do qual foram realizadas duas conferências no final dos anos 1990, 
reunindo especialistas internacionais de vários domínios, tendo a presente selecção de comunicações já sido anteriormente publicada numa edição em inglês (dos mesmos editores, Southern Europe and the Making of the European Union, 1945-1980s, SSM - Columbia University Press, Nova Iorque 2003). A segunda obra, organizada por Sebastián Royo, resulta das comunicações apresentadas numa conferência promovida pelo Centro de Estudos Europeus da Universidade de Harvard em Novembro de 2001. As presentes edições em português permitem divulgar melhor estes trabalhos e atingir um público mais vasto.

Comecemos por notar que com a aproximação dos anos 2000, se evidenciava a passagem do primeiro quarto de século da democratização (iniciada em Portugal e Grécia em 1974 e na Espanha no ano seguinte), dos quinze anos de integração portuguesa e espanhola na Comunidade Europeia (entrada em 1986) e de duas décadas para a Grécia (adesão a $1^{\circ}$ de Janeiro de 1981). Quer isto dizer que, decorrido o período inicial destes processos em que as considerações de natureza conjuntural tendiam a predominar, chegava a hora de ser assumida uma perspectiva de análise de mais longo prazo, de fazer reflexões mais aprofundadas sobre os resultados da democratização e da integração europeia e a forma como cada país se preparou para elas (a sua interligação foi óbvia nos três casos acabados de referir), e proceder às primeiras avaliações consistentes de desempenho. Estas duas obras colectivas inserem-se claramente nesta tendência. Quanto ao método comparativo de longo prazo que foi adoptado, ele tem, como é bem conhecido, as suas vantagens e desvantagens. Se, por um lado, permite tirar conclusões gerais com solidez indiscutível, por outro lado, pode fazer diluir a importância de aspectos ou períodos mais curtos, onde por vezes se passam coisas determinantes na evolução dos casos estudados, sobretudo quando se consideram isoladamente.

Após estas observações iniciais, importa fazer uma apresentação mais detalhada do conteúdo, sendo certo que só o podemos fazer limitadamente, tanto mais que se trata de duas obras que no conjunto somam mais de seiscentas páginas e em que participam cerca de uma vintena de autores.

Iniciando a nossa análise pela obra organizada por António Costa Pinto e Nuno Severiano Teixeira, refira-se a sua divisão em duas partes, respectivamente, perspectivas históricas e perspectiva comparadas. Os dois editores são também os responsáveis pelo primeiro capítulo da parte I que trata da posição portuguesa face à integração europeia entre 1945 e 1986, isto é das últimas décadas do Estado Novo e da primeira fase do Pós 25 de Abril. Os principais temas deste período são aí abordados - entre outros, a atitude do governo de Salazar perante o Plano Marshall, a participação na OCDE e depois na EFTA, os desafios colocados ao regime pelo prosseguimento do colonialismo, as mudanças económicas e sociais induzidas pelo desenvolvimento acelerado dos anos 1960-1973, o «caetanismo » e o Acordo Comercial com a CEE em 1972, e finalmente vários tópicos ligados à transição e institucionalização da democracia, com relevo para a emergência forte da opção política europeia. De notar que os autores se baseiam com frequência em pesquisas recentes, em particular sob a forma de teses de doutoramento e de mestrado.

O segundo capítulo foi escrito por Juan Carlos Pereira Castañares e Antonio Moreno Juste analisando o caso espanhol numa perspectiva temporal algo semelhante sob o signo da interrogação «A Espanha: no centro ou na periferia da 
Europa ? ». Cotejando com o artigo anterior, refira-se a forma como são destacados o desafio da modernização e o surgimento da Espanha na cena internacional. Quanto à primeira questão colocada a conclusão é clara : «O papel da Europa na recente história espanhola foi de grande estímulo que invariavelmente provocou a mesma resposta: a Europa tornou-se sinónimo de modernização política, económica e social» (p. 73), sublinhando ainda os dois autores a identificação espanhola «com tudo o que é europeu ». O capítulo 3 é da responsabilidade de António Varsori e trata de «a Itália e a integração europeia ». Como sabemos este país teve um percurso diferente dos outros da Europa do Sul já referidos, tendo sido um dos membros fundadores da Comunidade Económica Europeia. Todavia, é óbvio que a inclusão da Itália nesta obra se justifica por ser um bom termo de referência nas questões de integração e estar vitalmente interessada no processo de alargamento aos seus vizinhos do sul. O capítulo seguinte, escrito por Susannah Verney, examina a associação da Grécia com a Comunidade Europeia ; o facto de ter sido uma estratégia de Estado é particularmente destacado neste contexto. É também o capítulo mais extenso do conjunto, o que se justifica não só por ser o caso de um relacionamento mais longo (foi « o primeiro Estado a apresentar uma candidatura de associação à CEE»), mas também complexo, se por exemplo, pensarmos nas questões turca e balcânica envolventes. Na página 110 é referido o sucesso do então primeiro-ministro Karamanlis ao conseguir desvin-cular o seu país dos processos de adesão português e espanhol, criando uma " especificidade » que levou a Grécia a aderir alguns anos antes e a quebrar uma regra que, salvo situação excepcional como a da integração da Alemanha Oriental, se tem mantido até aos nossos dias "alargamentos por grupos de países ».

A parte 2 inicia-se com um trabalho de Alfred Tovias sobre as economias da Europa do Sul e a integração europeia que preenche um papel importante no conjunto. Com efeito, este autor tem escrito extensivamente sobre a questão, demonstrando conhecê-la bem, conseguindo mesmo transmitir as pequenas "nuances" de cada caso (Grécia, Espanha e Portugal) no que diz respeito aos padrões de integração na Europa; no final, faz algumas comparações pertinentes entre países do Sul e do Leste. O capítulo 6 de Geoffrey Pridham completa o anterior na perspectiva política, mostrando como a integração europeia contribuiu para a consolidação democrática na Europa do Sul. Não deixa de ser interessante assinalar aqui uma das suas conclusões principais « dos três países, foi Portugal que enfrentou os problemas mais exigentes de instabilidade política e económica, problemas esses que persistiram até bem dentro dos anos $80 »$ (p. 172). O capítulo 7 é da autoria de José M. Magone que se debruça sobre as atitudes dos cidadãos da Europa do Sul para com a integração europeia antes e depois da adesão. O estudo baseia-se nas sondagens do Eurobarómetro entre 1973 e 1999 e admite no final que as populações dos vários Estados membros estão a convergir gradualmente no sentido de uma apreciação positiva da integração europeia (p. 195). Provavelmente certo como tendência, mas este tipo de conclusões não deixa de ter algum carácter cíclico devendo ser aceite com reservas; aliás resta saber em que pé está a questão depois dos abalos dos anos 2000 (referendos negativos sobre o Tratado Constitucional, divisões a propósito do Iraque, possibilidade de adesão da Turquia, etc.). O último capítulo (8) é da responsabilidade de Leonardo Morlino, faz uma síntese das contribuições e aponta caminhos à investigação futura no domínio da « europeização da Europa do Sul». 
Uma objecção final deve ser feita sobre a Europa do Sul e a Construção da União Europeia 1945-2000, não se entende bem a mudança do título da edição inglesa para a portuguesa no que diz respeito ao período abrangido. Com efeito, quase todos os textos seleccionados, salvo o de José Magone, terminam o essencial da sua análise nos anos 1980, assim, era aconselhável que se mantivesse o período daquele edição e não estendê-lo até 2000, criando expectativas de abordagem que não se concretizam.

Por seu turno, Portugal, Espanha e a Integração Europeia: Um Balanço, de Sebastián Royo (ed.), está mais centrado na comparação entre Portugal e Espanha em função da mesma matriz (integração europeia), na maior parte dos capítulos a década de 1990 é incorporada e, de uma forma geral, o objectivo de avaliação é claramente assumido. Tal como o anterior, este livro também se encontra dividida em duas partes, na primeira (seis capítulos), a abordagem é predominantemente política e na segunda (cinco capítulos), o económico e o social dominam. Na introdução, da autoria de Sebastián Royo e Paul Christopher Manuel, começa-se por levantar uma série de tópicos (incluindo a questão de saber se estão ou não "vencidas as tensões históricas entre Espanha e Portugal») e é extraído um conjunto de lições sobre o processo de integração europeia de ambos os países.

O capítulo 1 foi escrito por Robert M. Fishman e intitula-se «Moldar a democracia : a União Europeia e as transformações políticas pós-autoritárias da Espanha e Portugal ». Ainda que não seja a nossa especialidade, há que reconhecer que se trata de um artigo muito interessante na medida em que tenta ir contra a corrente em vários aspectos (por exemplo, criticando «a ideia da interligação clara entre democratização e integração europeia », p. 64), atitude que é sem dúvida de louvar. Admitindo que é deliberadamente controverso, Fishman leva no entanto demasiado longe a sua atitude, revelando-se em particular, muito benevolente para com a elite portuguesa ao escrever «é possível que as elites portuguesas tenham feito um melhor trabalho do que as congéneres espanholas ao centrarem mais as suas atenções nos desafios específicos da sociedade portuguesa dentro do contexto mais amplo da integração europeia » (p. 76). Na verdade, só «muito teoricamente », tal se poderia admitir ${ }^{1}$. Pelo menos no que diz respeito à economia, Portugal apesar de pequeno, ao contrário do seu vizinho maior e do que recomendam os mais elementares ensinamentos teóricos permaneceu fechado, de maneira nenhuma aceitou, ao nível da competitividade e produtividade, os desafios amplos europeus, para já não falar dos mundiais, caindo mesmo e cada vez mais desde os anos 90, numa dependência regional estrita, em particular da própria Espanha². Pode ser

\footnotetext{
${ }^{1}$ Como mostraram A. Alesina \& E. Spolaore, na sua obra The Size of Nations (The MIT Press, 2003), num contexto de integração regional profunda e liberalização geral dos fluxos de comércio e investimento, ou seja num mundo sem barreiras significativas, as pequenas nações têm globalmente mais hipóteses que as grandes (o que se verifica também na UE com os casos irlandês, finlandês, dinamarquês, entre outros, bem demonstram), mas desde que as suas economias se adaptem às correntes efectivas mundiais, isto é, que se reformem e se reestruturem, o que infelizmente está longe de ter sido o caso português. A razão para esta diferença prende-se essencialmente com a dimensão dos mercados europeus e mundiais para as pequenas economias (em relação ao seu mercado interno), sendo o seu impacto menor para as grandes economias.

${ }^{2}$ Veja-se a este propósito J.R. SiLva, Portugal/Brasil : uma década de expansão das relações económicas, 
que a situação venha a mudar, mas a realidade dos anos 2000, com Portugal a divergir e a Espanha a convergir e a ser tomada como exemplo, até por Estados membros mais antigos, mostra a inconsistência da hipótese «simpaticamente » (para Portugal) levantada por Robert Fishman.

O capítulo 2 de Kerstin Hamman aborda o tema «integração europeia e sociedade civil em Espanha ». Trata-se de um estudo bem documentado acerca do impacto da integração europeia sobre vários aspectos da organização social em Espanha, em particular dos sindicatos (por exemplo, Comisiones Obreras e UGT) e dos pactos sociais em que participaram, uma questão de grande importância, muitas vezes subestimada neste tipo de estudos. O capítulo 3 é da responsabilidade de Luís Salgado Matos fazendo uma comparação entre Portugal e os países de Leste. Central no texto é a demonstração da força persistente da Nação-Estado (expressão que o autor prefere à usual «Estado-nação », na medida em que esta última tende a significar a subordinação do elemento nação). Salgado Matos termina com um anexo rico em informações quantitativas (na base de vários indicadores geográficos, económicos e sociais) sobre os Estados membros da Europa dos «Quinze » e os então ainda, na sua maioria, candidatos do Leste. O capítulo 4 é constituído por um trabalho de Marina Costa Lobo sobre as atitudes dos portugueses perante a UE (perspectivas sociais e políticas), baseado nos inquéritos do Eurobarómetro. É especialmente focada a relação entre o posicionamento dos partidos portugueses e dos seus apoiantes face à integração europeia; uma das conclusões mais importantes é a de que existe de facto uma clivagem entre eurocépticos e euroentusiastas, embora não seja muito saliente e tenha diminuído entre 1985 e 1999. Juan Díez-Nicolás é o autor do capítulo seguinte intitulado «o longo caminho da Espanha para a Europa », onde são apresentados vários quadros e gráficos sobre o grau de identificação espanhola com a Europa, confiança das instituições espanholas, regionais e europeias, atitudes face ao proteccionismo económico, etc. A conclusão final não é nova, mas é sem dúvida elucidativa: «Aparentemente, os espanhóis ainda não encontram razões de queixa da adesão à Europa, embora certamente manifestem atitudes proteccionistas quer em relação aos seus produtos, quer aos seus trabalhadores »(p. 188). No capítulo 6, Charles Powel revisita a adesão espanhola à UE através das suas principais fases : 19861991, os anos dourados; 1991-1996, a luta contra as contrariedades crescentes (de Maastricht ao afastamento de González); depois de 1996, a política europeia do governo Aznar. Powel termina o seu texto avisando a Espanha contra os perigos que corre ao procurar actuar acima das suas capacidades.

A parte II começa com um estudo de Jorge Braga de Macedo onde a integração de Portugal na Europa é resumida como sendo a de um «bom aluno com má constituição fiscal ». O texto tem informação interessante sobre o tema escolhido

Lisboa, Terramar, 2002 : 174-179 («A questão das relações comerciais entre Portugal e Espanha »). Ainda sobre a questão dos perfis diferentes do país pequeno e do país grande, aplicada a Portugal e Espanha, ver J. R. Silva, «Iberismo "localista” ou internacionalização dinâmica ? A identidade económica de Portugal na encruzilhada », Lusotopie, IX (2), 2002 : 179-192. Neste último artigo, considera-se a tendência em Portugal para sobrestimar a relação com Espanha, vulgo iberismo, como uma das manifestações do tradicional isolacionismo português. 
e destaca a grande oportunidade que sem dúvida foi a adesão do escudo ao SME em 1992, e analisa os frágeis fundamentos históricos da fiscalidade portuguesa, a tendência para vogar entre extremos e para o adiamento da sua necessária reforma. Teria sido oportuno que o autor também se tivesse interrogado sobre o não aproveitamento daquela oportunidade, designadamente sobre a forte correlação (negativa) entre indisciplina fiscal e a abertura competitiva da economia portuguesa? Isto é, se tivéssemos escolhido um caminho mais aberto e competitivo, isso exigiria necessariamente um maior controlo fiscal e macroeconómico (em vez do «despesismo» que antecedeu 1992); a prática consciente ou inconsciente de manter a economia de facto fechada (apesar de toda a retórica sobre a "pequena economia aberta » de muitos autores, e ainda que Braga de Macedo critique com razão, a nosso ver, os receios do «papão espanhol »), sem enfrentar os desafios europeus e mundiais ao nível da competitividade e produtividade, não será a mãe, pelo menos nas últimas décadas, da fácil disposição para a «má constituição fiscal »?

O capítulo 8, «A Espanha na UE : quinze anos podem não ser suficientes », escrito por Manuel Balmaseda e Miguel Sebastián, apresenta um panorama bastante completo da adesão da Espanha à União Económica e Monetária através dos processos de convergência nominal e real, sublinhando logo no início do texto que ela não se fez sem custos ( a convergência real da Espanha com a Europa cessou durante uma década, enquanto as reformas eram implementadas », p. 249) e concluindo que o referido espaço de tempo pode não ser suficiente para levar à convergência real com a UE. Os autores dão o devido realce ao sector externo ; o aumento do grau de abertura (muito maior que o português em termos de variação absoluta e relativa) e o papel do investimento directo estrangeiro são sublinhados. De uma lucidez pouco comum, Balmaseda e Sebastián consideram (p. 251): «De um modo geral, a integração europeia foi bastante benéfica para a economia espanhola. Mas isto não quer dizer que não tenha induzido certos custos que irão perpetuar-se. A Europa é responsável pela política agrícola e pela política de pescas espanholas, nenhuma delas propriamente eficiente, e interferiu nas suas relações externas, em particular com a América latina... o inerente proteccionismo comunitário representa um peso morto para as perspectivas do potencial crescimento espanhol » [sublinhado nosso]. Uma contribuição que muitos responsáveis da política e da economia em Portugal deviam ler, a fim de aprender seriamente qualquer coisa com o nosso vizinho.

«O redesenhar dos Estados-providência espanhol e português : o impacto da adesão à União Europeia » é o tema da responsabilidade da equipa Ana M. Guillén, Santiago Alvarez e Pedro Adão e Silva. Neste capítulo (9) é feita uma comparação bastante completa dos «Estados-providência » dos dois países, incluindo um anexo em que são integrados, em termos cronológicos, no contexto da política social europeia. São sobretudo de sublinhar as conclusões e a necessidade de aprofundar mais o estudo comparativo; neste sentido, destacamos a questão: " porque razão o mercado de trabalho evidencia uma tal diferença de comportamento em Portugal e Espanha em termos de emprego/índices de desemprego e padrões estruturais »? (p. 333). O capítulo 10 da autoria de José Silva Lopes adopta a mesma óptica comparativa focando « o papel do Estado no mercado de trabalho ». É apresentado um conjunto de gráficos e quadros comparando os dois países entre 
si e com a UE-15 sobretudo entre os anos 1980 e 1990, a partir de uma série de indicadores relativos ao mercado de trabalho (custos salariais unitários, salários reais, taxa de desemprego, etc.). No que respeita ao caso português, o autor termina num tom acentuadamente pessimista, que os factos vieram a confirmar, mas onde não se apresenta um caminho alternativo face a tendências previsíveis «a perda de competitividade dos seus custos laborais nos anos 1990 que já não poderá ser corrigida por desvalorizações das taxas de câmbio, como no passado - sugere que as perspectivas para as próximos anos são tudo menos encorajadoras » (p. 367).

O capítulo final (11) é da responsabilidade do organizador e, tal como se assinalou no princípio, é um dos que aborda a questão do intercâmbio de lições entre a Europa do Sul e a do Leste, escrevendo Sebastián Royo sobre «O alargamento de 2004 : lições ibéricas para a Europa pós-comunista ». É de sublinhar um dos quadros apresentados (p. 379) onde se evidencia em todos os casos, um menor apoio em Portugal do que em Espanha às diversas instituições e iniciativas da UE («ser membro », Comissão Europeia, UEM, novos membros, etc.) ${ }^{3}$. Já na parte final, e no espírito das referidas lições para os novos membros, escreve-se : «A ideia da Europa transformou-se numa força motriz impulsionadora de reformas e foi um factor fundamental para a consolidação da estabilidade política, a recuperação económica e a democracia » (p. 410).

Em síntese, no conjunto dos dois livros, encontramo-nos perante um trabalho comparativo válido e de grande utilidade. De acordo com o que se escreveu no início, o único senão residirá talvez no facto da importância de certos períodos e questões mais precisas se diluírem na comparação geral. Com efeito, e no que respeita a Portugal, sem dúvida um dos dois países que está no centro da maioria das análises, não se prevê, pelo menos de forma clara, o já relativamente longo período de divergência real face à UE iniciado por volta de 2000, embora os seus sinais já fossem evidentes no final dos anos $1990^{4}$. Isto é, não se levanta uma das questões incontornáveis dos últimos anos neste contexto, pelo menos para o caso português. Importa acrescentar que alguma capacidade de intuir as tendências vindouras pode revelar-se de uma enorme vantagem, em termos de valorização futura dos textos. Não obstante esta crítica, estão de parabéns os organizadores e intervenientes das duas obras que podem e devem ser aprofundadas e actualizadas em muitos aspectos.

\section{Fevereiro de 2007, Joaquim Ramos Silva}

\footnotetext{
${ }^{3}$ Quando, de acordo com a teoria a que se aludiu em nota anterior, «deveria » acontecer precisamente o contrário.

${ }^{4}$ Ver a nossa comunicação: "The Portuguese economy in the light of Irish experience. A comparison of the 1990 decade », Issues on the European Economics: Recent Developments, Actas do $3^{\circ}$ Encontro Internacional sobre Economia Europeia, 10-11 de Dezembro de 1999, Lisboa, Instituto Superior de Economia e Gestão, Centro de Estudos de Economia Europeia e Internacional, [2000] : 221-242; onde também se apresenta a confirmação empírica do fecho relativo da economia portuguesa, por exemplo no confronto com a Espanha, assunto várias vezes referido ao longo desta recensão.
} 